\title{
COVID-19 in oncology palliative care: psychological stress from the perspective of psychodynamics at work
}

\author{
Alex Sandro de Azeredo Siqueira, Enéas Rangel Teixeira, Daianny Arrais de Oliveira da Cunha, \\ Fernanda Barcellos Santiago, Endi Evelin Ferraz Kirby, Luciene Miguel Lima Neves \\ Federal Fluminense University (UFF), Niterói, Rio de Janeiro, Brazil \\ Contributions: (I) Conception and design: AS de Azeredo Siqueira, ER Teixeira, DA de Oliveira da Cunha, F Barcellos Santiago; (II) Administrative \\ support: AS de Azeredo Siqueira, ER Teixeira, EE Ferraz Kirby, LM Lima Neves; (III) Provision of study materials or patients: AS de Azeredo \\ Siqueira, DA de Oliveira da Cunha, F Barcellos Santiago, EE Ferraz Kirby, LM Lima Neves; (IV) Collection and assembly of data: AS de Azeredo \\ Siqueira, ER Teixeira, DA de Oliveira da Cunha, F Barcellos Santiago; (V) Data analysis and interpretation: AS de Azeredo Siqueira, ER Teixeira, EE \\ Ferraz Kirby, LM Lima Neves; (VI) Manuscript writing: All authors; (VII) Final approval of manuscript: All authors. \\ Correspondence to: Alex Sandro de Azeredo Siqueira. Federal Fluminense University (UFF), Rua Doutor Celestino, 74. Centro, 24220045 Niterói, RJ, \\ Brazil. Email: assiqueira@hotmail.com.
}

Background Identify the main stressors of the nursing team in assisting patients in oncology palliative care with suspicions and confirmed for COVID-19.

Methods: Qualitative, descriptive and exploratory study with theoretical framework in the psychodynamics of work, carried out in the emergency and hospitalization sector of a national reference center for cancer treatment in Rio de Janeiro/Brazil. The semi-structured interview was used to collect the data, from April to May 2020. The data were organized and analyzed using the Collective Subject Discourse (CSD) method with the aid of the Qualiquantisoft ${ }^{\circledR}$ software.

Results: Twenty members of the nursing team participated (10 nurses and 10 nursing technicians). After the analysis, three CSDs with their respective central ideas (CI) emerged. The CSD software, Qualiquantisoft ${ }^{\circledR}$, also provided a quantitative analysis of the responses, in which $12(60 \%)$ of the respondents believe that the main stressors are associated with work organization, $6(30 \%)$ of the respondents believe that the main stressors are associated to work relationships and $2(10 \%)$ of respondents believe that the main stressors are associated with working conditions.

Conclusions: The adaptations that took place in the management of care and in the organization of work, to better serve patients in oncology palliative care with suspicions and confirmed for COVID-19, brought greater impact and psychological stress on the nursing team. Considering all the difficulties and influences that the nursing team members are facing in this pandemic moment by COVID-19 associated with palliative oncology care, it is believed that identifying the source of the psychological stress presented by them may contribute to them have a more effective, humanized and holistic care, in addition to spreading knowledge to nursing and other segments of the health area and bringing subsidies to other scientific productions, as well as highlighting the importance of early detection of psychological stress as a way of preventing impacts physical and psychosocial problems caused by work.

Keywords: Psychological stress; nursing team; palliative care; COVID-19; pandemic

Submitted Jan 09, 2021. Accepted for publication Mar 05, 2021.

doi: $10.21037 /$ apm-21-56

View this article at: http://dx.doi.org/10.21037/apm-21-56 


\section{Introduction}

\section{Background}

In January 2020, the World Health Organization (WHO) declared the outbreak of a new coronavirus disease (COVID-19) to be a Public Health Emergency of International Interest. This rapid increase in the confirmation of cases and deaths in an unprecedented pandemic, generated great impacts such as stress, anxiety and depression, not only on the nursing team, said team "on the front line", but on the entire world population (1).

Of all the professionals working on the front line against COVID-19, the nursing team is the most susceptible to psychological stress due to several factors such as: prolonged contact, risk of contamination, shortage of personal protective equipment (PPE), lack of technical/theoretical knowledge about the new virus of the coronavirus family, as well as ethical and moral issues of the profession (2).

These factors can generate great psychological pressure on the members of the nursing team, which can foster feelings of loneliness and helplessness, or a series of dysphoric emotional states, such as stress, irritability, physical and mental fatigue and despair. Work overload and symptoms related to stress make members of the nursing team especially vulnerable to psychological suffering, increasing the chance of developing psychiatric disorders. The recognition of risks and the planning of interventions aimed at reducing the damage to psychological health of these professionals involved in the care of patients infected with COVID-19 must be prioritized and actions must be established and implemented (3).

The COVID-19 pandemic had a profound impact on all areas of hospital care and would be no different with assistance to patients undergoing palliative cancer treatment.

In the context of care for cancer patients affected or not by COVID-19, care management must include palliative care. The WHO defined this type of care as an approach that aims to improve the quality of life of patients and family members through the prevention and relief of suffering, early identification, impeccable assessment and treatment of pain and other physical, psychosocial and spiritual (4).

Patients with advanced cancer in exclusive palliative care tend to have shorter survival justified by the weight of the disease and suspension of anticancer treatment. It is assumed that this group of individuals infected by COVID-19 has even less survival, which requires the support of multiprofessional teams of workers in palliative care to relieve suffering, control symptoms and promote quality of life and death. One of the main challenges of the Unified Health System (SUS) is to improve care for these patients, offering comprehensive care and optimizing available resources (5).

The reactions of the nursing staff to the stress of the current pandemic must be viewed from an occupational health and safety perspective. Stress and burnout were recognized internationally as professional risks for the nursing staff before the pandemic. While research suggests that occupational and personality factors play a role in burnout, in 2019 the WHO declared burnout an occupational phenomenon-rather than a medical condition. Characterized by feelings of exhaustion, dismissal from work and a sense of diminished professional fulfillment, burnout is considered the result of chronic work stress that the individual is unable to manage. The beginning of the COVID-19 pandemic increased the work stress of the already overworked nursing team, putting their mental health and well-being at risk (6).

The new pandemic COVID-19 is a public health emergency unprecedented in modern history. In addition to the biological context, and due to the wide and lasting changes that it can cause in daily life, facing it represents a challenge to psychological resilience. Previous studies have shown that epidemics and outbreaks of disease contamination have been accompanied by drastic individual and social psychosocial impacts, which have ended up spreading more than the epidemic itself. Given this scenario, it is extremely important to identify the main stressors of the nursing team, seeking to implement strategies to deal with difficulties, increase well-being and reduce psychological stress, in a harmonious way and respecting the time available and the needs of each member of the nursing team in caring for patients in oncology palliative care with suspicions and confirmed for COVID-19 (7).

We present the following article in accordance with the COREQ reporting checklist (available at http://dx.doi. org/10.21037/apm-21-56).

\section{The objective of the study}

The present study aims to: identify the main stressors of the nursing staff in assisting patients in oncology palliative care with suspicions and confirmed for COVID-19 and to provide subsidies for measures of psychological interventions during the pandemic by COVID-19 and in the future. 


\section{Methods}

The study was conducted in accordance with the Helsinki Declaration (revised in 2013). The study was approved by the ethics committee of the National Cancer Institute (INCA), Rio de Janeiro/Brazil (N: 3.992,180) and informed consent was obtained from all individual participants.

\section{Study design and participants}

This is an exploratory descriptive study with a qualitative approach.

The Collective Subject Discourse (CSD) was adopted as the methodological framework and the psychodynamic framework in the work of Christophe Dejours as the theoretical framework. The CSD is a method and technique of data processing that allows the clear interpretation of a given social representation, in addition to identifying the real thoughts, beliefs and feelings of individuals, through statements. The CSD is a synthesis discourse, built from fragments of testimonies from the community, with a similar meaning and organized in order to rescue the sense of collective opinion, gathering central ideas of a studied phenomenon (8). The psychodynamics of Christophe Dejours' work, on the other hand, is a discipline that is built by the work itself, focusing on the importance of the worker in the organization of work and articulating all its subjectivities. In addition to being a discipline, Work Psychodynamics is a theory that seeks to analyze the origin of suffering, wear and pathologies, but also satisfaction, health and pleasure at work (9).

The study was carried out in a hospital unit specialized in palliative oncology care, more precisely in the sectors of emergency and hospitalization, sectors intended for patients in palliative oncology care and with suspicion end confirmed for COVID-19. These locations were chosen to carry out the study because they make it possible for the nursing team to contact patients in oncology palliative care and with suspicions and confirmed for COVID-19. This unit belongs to a national reference center for cancer treatment, located in the city of Rio de Janeiro, RJ/Brazil.

During the pandemic and research data collection, a total of 40 professionals from the nursing team (12 nurses and 28 nursing technicians) worked in the hospitalization and emergency department of patients in oncology palliative care with suspicions and confirmed for COVID-19.

All members of the nursing team in this study were recruited by convenience sample and occurred through individual invitation by the researcher.

For inclusion in the study, the following criteria were adopted: members who worked in the nursing team in palliative oncology care for more than 1 year and who were in direct care for patients with suspicions and confirmed for COVID-19. Team members who were on sick leave or maternity leave were excluded.

The sample is not probabilistic and intentional, and the number of participants was defined a posteriori, based on the criterion of saturation sampling, according to qualitative methodology studies. In qualitative research, the sample size is generally not predetermined. The number of participants depends on the number needed to inform all the important elements of the phenomenon under study. In other words, the sample size is sufficient when additional interviews or focus groups do not result in the identification of new concepts, an end point called data saturation (10).

To obtain the data from this study, the semi-structured interview technique was used, using the initial question: what are the main stressors of the nursing team in assisting patients in oncology palliative care with suspicions and confirmed for COVID-19?

Twenty semi-structured interviews (10 nurses and 10 nursing technicians) were conducted with individuals eligible for the study and with informed consent. This sample size made it possible to saturate the data, which made new notions or themes no longer raised in new interviews. There was no refusal to participate (8).

Nurses and nursing technicians were associated because they are in the same workplace and for providing direct assistance and nursing care to patients in suspected and confirmed oncology palliative care for COVID-19.

\section{Study measures}

To obtain the data from this study, the semi-structured interview technique was used, using the initial question: what are the main stressors of the nursing team in assisting patients in oncology palliative care with suspicions and confirmed for COVID-19?

\section{Data collection}

Data were collected in April and May 2020, during the working day in the meeting room in the hospitalization sector, so as not to cause harm to the nursing care provided to patients. There were no difficulties in conducting the interviews, since the meeting room is a reserved, quiet and 
air-conditioned environment.

We opted to conduct the interviews during working hours due to fears and tensions in this pandemic moment, as the research may present minimal risks related to emotional reactions. Due to the emotional context, the research participant can be referred to the Psychology Service or to the emergency room of this unit.

The interviews were conducted in Portuguese with an average duration of 15 minutes and 8 seconds. The recordings were made with the aid of an electronic device in MP3 format.

\section{Statistic analysis}

The analysis was carried out in Portuguese. The recordings of the interviews were transcribed and archived in word processing software (Microsoft Word 2019), to capture with greater accuracy the answers from the questioning. In order to maintain the anonymity of the participants, their statements were represented in this study by the letter (E) for nurses and the letters (ET) for nursing technicians, complemented by an Arabic number that represents the order in which the interview was conducted, by example, E1 to E10 and ET1 to ET10.

Empirical data were organized based on the CSD technique. For this, the following methodological figures of the transcribed verbal material were sought: the key expressions (CE), the central ideas (CI) and anchoring (CA). The CI brings the essence of the discourse emitted by the individual, the $\mathrm{CE}$ are literal transcriptions of part of the interviews, which provide the essence of the discursive content and the CA is the explicit linguistic manifestation of a given theory, or ideology, or belief, or value of the speech. The CSD consists of strata of the speeches transcribed with the same CI, the same CE and CA (8).

The collected statements were methodologically treated using the Qualiquantisoft ${ }^{\circledR}$ software. In this tool, the qualitative dimension is expressed in the CSD and the quantitative dimension in the frequency of sharing speeches between individuals, that is, speeches with the same CI. Therefore, after all interviews were transcribed and typed, the software helped operationalize it in categories, elaborate the speech, as well as the production of quantitative reports, which provides the percentage of individuals who contributed with their key expressions related to the central ideas (8).

These units were grouped by the convergence of meanings and aggregated into theoretical categories, giving rise to three central ideas. The inference and interpretations of the data were based on the psychodynamics of Christopher Dejours' work.

To carry out the translation from Portuguese to English, direct translation and back-translation were used. An English-speaking author translated the original data into an English version. Phrases that are not in accordance with the cultural context were discussed and changed by the members of the research group.

\section{Results}

Regarding the categorization of the sample, the study had a total of 20 members of the nursing team, 10 nurses and 10 nursing technicians. Of the 20 participants interviewed, $85 \%$ were women and $15 \%$ men. The age range ranged from 33 to 54 years, with $60 \%$ from 33 to 39 years, $20 \%$ from 47 to 53 years, $15 \%$ from 40 to 46 years and $5 \%$ from 54 to 60 years. As for years of experience, $50 \%$ said they had 8 to 11 years of experience, $25 \%$ said they had 4 to 7 years of experience, $20 \%$ said they had 12 to 15 years of experience and $5 \%$ said they had to 16 to 19 years of experience.

From the question (what are the main stressors of the nursing team in assisting patients in oncology palliative care with suspicions and confirmed for COVID-19?), three CSDs emerged with their respective ICs. The CSD software, Qualiquantisoft ${ }^{\circledR}$, also provided a quantitative analysis of the responses, in which 12 (60\%) of the respondents believe that the main stressors are associated with work organization, $6(30 \%)$ of the respondents believe that the main stressors are associated the relationships at work and $2(10 \%)$ of the interviewees believe that the main stressors are associated with working conditions.

\section{Central idea A: main stressors are associated with work organization}

The organization of work encompasses issues related to how work is carried out, related to management, from the division of labor, the content of tasks resulting from it, support to professionals, power relations between hierarchical levels, responsibilities linked to positions and all the training given to perform the tasks.

The speeches reveal that the uncertainties due to this unprecedented pandemic generate a great negative influence on the professional, as creating a new flow of care, and adapting it to palliative oncological care generates an 
increase in pressure at work.

CSD 1: "Understanding the whole process and thinking about what can be adaptable for the job is a heavy task. Mental stress and lack of patience, all very new and various information, even generating irritability. Multiple information. The pressure at work has increased considerably, both physically and mentally. There are many doubts and I feel insecure. The disorganization in the flow of care and the lack of definition of the roles of the sectors during the patient's stay from screening to hospitalization are bad. My work dynamics have changed a lot, today I play a totally different role" (E2, E5, E7, E8, E9, E10, ET3, ET5, ET7, ET8, ET9, ET10).

The change in the management of nursing care under palliative principles, triggers psychological stress. Not promoting assistance based on palliative care, assisting in mourning and promoting a good death, established suffering.

CSD 1: "The workload increased due to the probibition of the family member/caregiver. That organization of the care network and the presence of family members in the process of death and dismissal of patients was lost. The feeling of not performing palliative care as it should be is terrible, not due to negligence, but due to the circumstances imposed by the pandemic. Very touching and sad. It is difficult to see the patient arriving in care at the end of life without his family member or caregiver, this has demotivated and sometimes I would not like to be here living it. Seeing the patient die in solitude is very touching and sometimes devastating. Death is not the worst, but death in solitude touches me a lot and goes against total palliative principles" (E2, E5, E7, E8, E9, E10, ET3, ET5, ET7, ET8, ET9, ET10).

In addition to influencing the change in care management, the new profile of the suspected and confirmed patient for COVID-19 generated negative mobilization, as the risk of contamination was increased with the insertion of a virus in the oncology patient's hospital context.

CSD 1: "The patient changed his characteristics, before he had terminal cancer and demanded a lot of work, but the cancer is not transmissible. Now, in addition to terminality, it can transmit an extremely unknown disease to us" (E2, E5, E7, E8, E9, E10, ET3, ET5, ET7, ET8, ET9, ET10).

Another piece of data was the overload of nursing, as they assume a large part of the care processes, due to the restrictions on visits to patients by other members of the multidisciplinary team.

CSD 1: "Not all members of the multidisciplinary team are coming in to see the patient, due to visiting restrictions and to reduce contact, and this de-characterizes palliative care, reduces the view of care, the patient ends up not being seen by everyone and in a way it overloads the nursing team that ends up taking over all the processes" (E2, E5, E7, E8, E9, E10, TE3, ET5, ET7, ET8, ET9, ET10).

Work can mobilize the professional both negatively and positively. We can observe in the speech, reports of positive or positive changes in terms of the way of seeing and valuing life. Being able to help other members of the nursing team re-signified and positively mobilized the professional, through the feeling of usefulness. The appreciation, recognition and integration of the professional in the work process also mobilized the team in a positive way.

CSD 1: "I started to see things in a different way, mainly in relation to money, the relationship of being here, the relationship with co-workers, the relationship with my superiors. I value things differently, so I reframed a lot, so it was positive, reframing and being closer to people. I help not only the patients, but their teammate in the dressing and the dressing. I belp and receive help all the time, this is wonderful and has changed me a lot" (E2, E5, E7, E8, E9, E10, ET3, ET5, ET7, ET8, ET9, ET10).

Another form of positive mobilization of work on the professional was observed in the discourse on religion. The work mobilizes the professional in the search for faith and spirituality.

CSD 1: "I turned more to my religion, seeking help and support. I pray I ask God to give me strength in my day. I seek my spiritual belief and strength in everyday life" (E2, E5, E7, E8, E9, E10, ET3, ET5, ET7, ET8, ET9, ET10).

\section{Central idea B: main stressors are associated with labor relations at work}

Work relationships are primarily social and intersubjective, as it is from work that individuals create social bonds, encompassing hierarchical and collective interactions, in addition to relating to external entities, involving different types of relationships. We can say that labor relations are the social bonds built from the context of work organization, whether with bosses and colleagues, or with other workers. This integrates the relationship that the subject has with himself and the form of meanings of work for his life, his livelihood and his personal fulfillment.

In the discourse we can observe two mobilizing aspects, one for reasons of empathy and projection of the other's disease itself, causing sadness, and the absence of the other, due to illness, which generates work overload, that is, we have physical and psychic influences. 
CSD 2: "Watching the colleagues get sick was terrible, because at the same time that I was sad to see them sick, I projected that it could be me or that I would be next, so everything was much more difficult. With the removal of sick colleagues and reduced $H R$, it generated a lot of overload. The overload and illness of the team members make me wonder if it is really worth being on the front line" (E1, E2, E6, ET1, ET4, ET6).

It was reported that the union and protection of the other due to the increased risk of contamination by COVID-19 generated a state of companionship and help, an important mobilization in the process of job satisfaction and pleasure.

CSD 2: "This pandemic brought together members of the nursing team. A meeting of true companions, with the same harmony and the same solidarity. Today I work with a care I didn't have before, and people are protecting themselves more. I feel that positivism is contagious, I realize that it generates influence in our work, so everyone ends up being infected with this positivism, generating a feeling that we will overcome this difficult moment" (E1, E2, E6, ET1, ET4, ET6).

\section{Central idea C: main stressors are associated with working conditions}

The working conditions include physical, chemical and biological issues of the work organization, as well as aspects related to the health and safety of the professional.

Working conditions can be responsible for mental disorders when they are configured as: overwork; exacerbated demands on the worker's skills; monotony and even labor harassment. In this way, the conditions in which the work is performed can turn it into pleasant/favorable or a painful and painful experience, which can cause the individual's suffering.

The negative influence on nursing due to safety protocols can be both physical and psychic. The concern with the other and the duration of use of the PPE's, in addition to skin lesions, heat and weight are contributors to psychological and physical stress.

CSD 3: "I feel very tired and tense in having to repeat the whole process of dressing up and getting out. Extremely difficult to breathe with the mask and absurd heat, in addition to the weight of the cloak. I feel both physical and mental tired from all worry. My face and ears are sore from wearing the mask for 12 hours. The concern with protection is collective and I am always attentive to my colleague. I am afraid of making mistakes in the sequence of dressing and lack of dressing, as we have never experienced that" (E3, ET2).

It can be seen in the speech how important training and guidelines are to reduce negative influences arising from this new pandemic by COVID-19. The guidelines, training and provision of PPE's were seen as mobilizers of pleasure and not of suffering.

CSD 3: "They were provided and we are receiving training from PPE's, but what worries me is the constant use, the heat, the weight and the dermatological marks and wounds caused by prolonged use" (E3, ET2).

According to the interviewees, attitudes at work generated influences on workers' lives and they improved attitudes towards hygiene beyond the hospital walls.

CSD 3: "Biosafety habits, such as the use of masks and gloves, were rethought, even at home we improved the cleaning and washing habits of fruits and vegetables, in addition to the hands" (E3, ET2).

\section{Discussion}

The emergence of the COVID-19 pandemic generated multiple changes in the flow of hospital care and in the management of the nursing team care process. Adaptation to the new pandemic scenario in record time was established, but little was known about the new coronavirus and we had no way of predicting the impact on the nursing team, considered the front line.

The nursing team is one of the categories that most have contact and interaction with patients in palliative care, and providing assistance to these patients during the COVID-19 pandemic can be a source of pleasure or suffering. Satisfying the physical, emotional and spiritual needs of patients and family members/caregivers represents a major challenge for members of the nursing team, due to the unusual character of the moment (11).

Dealing with a large-scale pandemic also requires a robust hospital structure that allows for quick and adequate decision-making for the control and spread of the virus, in addition to a network integrated with Public Health systems which allows better coping by the professionals involved to the new health reality (12).

In Brazil, issues of political interest have generated polarization and controversy about the approach and behavior during the pandemic by COVID-19. The lack of convergent thinking has brought doubts and fear to the entire scientific community, thereby delaying the creation of a new flow of care and decision-making, contributing to the increase in contamination in the population and thereby creating an overload in hospital care (13).

With the COVID-19 pandemic, several factors are 
predictors for the emergence of psychological stress by the nursing team, as they are the professionals who spend most of their time with patients, not to mention doubts and changes in the dynamics and conditions of care. work still so incipient.

In view of this critical situation and with the increasing number of suspected and confirmed cases for COVID-19, the overwhelming workload, added to the scarcity of PPE, wide media coverage, lack of specific medications, inadequate support for nursing and the need to restructure care to better adapt to the new clinical profile of patients with suspicions and confirmed for COVID-19, contributed to the increase in the occurrence of psychological stress by the nursing team (14).

In this moment of pandemic by COVID-19, it is essential to reflect the management of care in palliative cancer care, however, this is not an easy task. Modifying a service routine and adapting it to the principles of palliative care, requires knowledge and work, especially in the implementation and training, deconstructing a past and creating a new present/ future.

The professional practice of nursing in palliative oncology care associated with the COVID-19 pandemic is being marked by multiple demands, such as: dealing with pain, suffering of patients and family, death, fear of the unknown, fear of contamination by a new virus and the constant changes in protocols and guidelines in care management (4).

The patient of palliative oncology care has undergone a change in his clinical profile, as it is known that cancer is not transmissible, however with the emergence of COVID-19 a new virus is inserted in the care setting and the oncological patient who previously did not transmit disease passes to offer risk of contamination.

Moral dilemmas, arising from internal pressures (fear, inability to cope with suffering, lack of knowledge) or external pressures (hierarchical pressure, failures in communication and organizational problems, lack of resources and support from other services), are accentuated in periods of pandemic, which can generate great psychological stress on the members of the nursing team (15).

Palliative care is not based on protocols, but on principles. The family is remembered, therefore also assisted during and after the patient's death, in the period of mourning (16). The inclusion of the family/caregiver in the participation of care is crucial, as it will allow them to have a better adaptation to the grieving process, since they will feel that everything was done by the patient (17).

With the orientation towards social distancing and the withdrawal of the family member/caregiver from the care process, the nursing team assumed all the demands arising from the patients, generating work overload.

The influence of the absence of the family member/ caregiver is revealed not only by the issue of increased demand for work, but also by ethical issues of the profession in the care process. By removing the family member/ caregiver from your loved one at the time of death, we steal traditional mourning practices. As a result, the professional of the nursing team suffers a great negative impact, generating frustration for not having reached their work objective, based on good death (18).

Self-confidence can be impacted because, in addition to feeling incapable for not being able to meet the demands arising from the COVID-19 pandemic, the members of the nursing team may feel shaken for having betrayed the ethical sense and their moral values.

In health, the work aims at the therapeutic action of care. The nursing work object consists of people who need health care, with all the complexity and subjectivity of the human being (19). Failure to provide care in its entirety generates negative mobilization on the nursing team.

Another aspect fostered by the COVID-19 pandemic in palliative oncology care, were the restrictions on the care of other members of the multidisciplinary team, which are so important in the care process, mainly because we know that palliative care is not possible without a multidisciplinary team, succumbing then, in the fragmentation of the connections of knowledge and dialogue, in addition to creating work overload for the other team members. We know about the guidelines for isolation and restrictions for the visits of professionals, but it is necessary to rethink issues related to the psychodynamics of work, trying not to overburden any class.

In the chain of actions to protect workers, contact restriction is one of the methods used, however, in the case of COVID-19 the effectiveness of EPI is considered consistent, being related to the provision and adequate training of teams of workers (12).

It is necessary that even in a pandemic period, organizations make room for collective discussion and that professionals can express their anxieties and opinions about the management of nursing care. Responsibilities need to be shared and the search for solutions must be discussed. The professional must be integrated into the entire work process and not just perform it. 
For there to be good nursing care, the professional needs to experience a feeling of adequacy and well-being, influenced by his values and those of those with whom he interacts, he must know his emotions, remaining aware of them to use them in the conduct of his behavior, reducing suffering.

According to Maslow, man is motivated when his needs such as self-realization, self-esteem and other related factors are met. Motivation is a set of actions that are manifested in various ways influencing the individual in his conduct (20).

For Dejours, the origin of suffering, in turn, also has its roots in the unique history of every person. Suffering is individualized and depends on the social and psychological construction of each person, along with work and its dimensions: organization, relationships and conditions (9).

Living with other members of the nursing team can influence positively or negatively. It will be positive for having the presence of the other, generating security, even during the process of dressing up and de-dressing, mobilizing attitudes of help, cordiality, zeal and affection. It will be negative for seeing in the other, who has often been contaminated, his own reality, confronting the other's illness as if it were his own. It is worth remembering that the illness and the withdrawal from the other does not only generate psychic influences, since it will be less of a professional, resulting in work overload (21).

According to the psychodynamics of the work of Christopher Dejours, who studies the issues of health and illness of the professional as well as his defenses to deal with problems, there is no classic separation inside and outside work (22). The issue of displacement and transportation, as well as the school issue of children, had a great impact on the members of the nursing team, in addition to the fear of bringing contamination into their home.

In the work process, managers play a key role in reducing the psychological stress of their employees, with attitudes such as: transmitting appreciation, taking psychological stress seriously, creating an atmosphere of trust, promoting self-care, offering professional support, establishing a clear communication and making clear the attributions relevant to each category, without overlapping values and functions. Authoritarian and unshared management will certainly evoke suffering and psychological stress in your collaborator. The organization that welcomes the professional offers discharge routes, turning the final product of work into a source of pleasure (23).

Even with all the difficulties arising from the associated COVID-19 pandemic and the lack of administrative and governmental maturity, it is possible for the professional to experience the sensation of pleasure at work. The resignification of feelings of the members of the nursing team, through the recognition and gratitude of a society, in such a critical moment, transports the professional from a place of suffering and difficulties to a place of pleasure through what is done.

The study reveals situations considered primordial with regard to the work of nurses in nursing care in palliative oncology care, taking into account their subjectivity.

This study is a starting point in an unprecedented situation and in an essential historical moment, but we must emphasize that it has some limitations. The study took place in the initial period of the pandemic by COVID-19 in Brazil, thus having very unknown characteristics, in addition to the adaptation and initial training, in addition, the participants were only members of the nursing team, with the expansion of the entire multidisciplinary team being important. I believe that the data provided here reveal very useful information to be extrapolated in new studies still in the same pandemic, as in future pandemics.

\section{Conclusions}

In the current pandemic of COVID-19, members of the nursing team are facing major challenges in dealing with the crisis. Not promoting assistance based on palliative care, assisting in mourning and promoting a good death, established suffering. Palliative Care is not based on protocols, but on principles and not providing care in its entirety generates negative mobilization on the nursing team.

In this situation, these professionals are faced with specific stressors and risks, not only for physical health, but also for mental health. The occurrence of psychological stress, due to this unprecedented pandemic associated with the specific characteristics of palliative cancer care, represents a reaction considered normal and understandable, but it is extremely important to try to minimize it, treat it and care for it.

Action is needed to mitigate the side effects of the pandemic by COVID-19, an action that can be supported by social and behavioral sciences. However, many of the implications described here may also be relevant to future pandemics and public health crises.

Considering all the difficulties and influences that the nursing team members are facing in this pandemic moment by COVID-19 associated with palliative oncology care, it 
is believed that identifying the source of the psychological stress presented by them may contribute to them have a more effective, humanized and holistic care, in addition to spreading knowledge to nursing and other segments of the health area and bringing subsidies to other scientific productions, as well as highlighting the importance of early detection of psychological stress as a way of preventing impacts physical and psychosocial problems caused by work.

\section{Acknowledgments}

We thank all members of the nursing team, indispensable in this fight.

Funding: None.

\section{Footnote}

Reporting Checklist: The authors have completed the COREQ reporting checklist. Available at http://dx.doi. org/10.21037/apm-21-56

Data Sharing Statement: Available at http://dx.doi. org/10.21037/apm-21-56

Peer Review File: Available at http://dx.doi.org/10.21037/ apm-21-56

Conflicts of Interest: All authors have completed the ICMJE uniform disclosure form (available at http://dx.doi. org/10.21037/apm-21-56). The authors have no conflicts of interest to declare.

Ethical Statement: The authors are accountable for all aspects of the work in ensuring that questions related to the accuracy or integrity of any part of the work are appropriately investigated and resolved. The study was conducted in accordance with the Helsinki Declaration (revised in 2013). The study was approved by the ethics committee of the National Cancer Institute (INCA), Rio de Janeiro/Brazil $\left(\mathrm{N}^{\circ}: 3.992,180\right)$ and informed consent was obtained from all individual participants.

Open Access Statement: This is an Open Access article distributed in accordance with the Creative Commons Attribution-NonCommercial-NoDerivs 4.0 International License (CC BY-NC-ND 4.0), which permits the noncommercial replication and distribution of the article with the strict proviso that no changes or edits are made and the original work is properly cited (including links to both the formal publication through the relevant DOI and the license). See: https://creativecommons.org/licenses/by-nc-nd/4.0/.

\section{References}

1. Ozamiz-Etxebarria N, Dosil-Santamaria M, PicazaGorrochategui $M$, et al. Stress, anxiety, and depression levels in the initial stage of the COVID-19 outbreak in a population sample in the northern Spain. Cad Saude Publica 2020;36:e00054020.

2. Soares SSS, de Oliveira Souza NVD, Silva KG, et al. Covid-19 pandemic and rational use of personal protective equipment. Rev Enferm UERJ 2020;28:e50360.

3. Ornell F, Halpern SC, Kessler FHP, et al. The impact of the COVID-19 pandemic on the mental health of healthcare professionals. Cad Saude Publica 2020;36:e00063520.

4. Florêncio RS, Cestari VRF, Souza LC, et al. Cuidados paliativos no contexto da pandemia de COVID-19: desafios e contribuições. Acta Paul Enferm 2020. doi: 10.37689/acta-ape/2020ao01886.

5. Ting FI, Ylanan AM, Sacdalan DL. The pain of sending away cancer patients amidst the COVID-19 pandemic. EJMO 2020;4:349-50.

6. Arnetz JE, Goetz CM, Arnetz BB, et al. Nurse Reports of Stressful Situations during the COVID-19 Pandemic: Qualitative Analysis of Survey Responses. Int J Environ Res Public Health 2020;17:8126.

7. Dal'Bosco E, Floriano L, Skupien S, et al. A saúde mental da enfermagem no enfrentamento da COVID-19 em um hospital universitário regional. Rev Bras Enferm 2020;73:e20200434.

8. Santos L, Santos Júnior C, Zimpel S, et al. Metodologia do discurso do sujeito coletivo na avaliação das contribuições de um projeto de extensão universitária. Revista Docência do Ensino Superior 2020;10:1-17.

9. Dejours C, Abdoucheli E, Jayet C. Entre o desespero e a esperança: como reencantar o trabalho. 1st ed. São Paulo: Atlas, 2015.

10. Demo P. Práticar ciência - Metodologias do conhecimento Científico. 1st ed. São Paulo: Saraiva, 2011.

11. Pai RR, Nayak MG, Sangeetha N. Palliative care challenges and strategies for the management amid COVID-19 pandemic in India: perspectives of palliative care nurses, cancer patients, and caregivers. Indian J Palliat Care 2020;26:S121-5.

12. Gallasch C, Cunha M, Pereira L, et al. Prevention related 
to the occupational exposure of health professionals workers in the COVID-19 scenario. Rev Enferm UERJ 2020;28:e49596.

13. Justo AM, Bousfield ABS, Giacomozzi AI, et al. Communication, Social Representations and Prevention Information Polarization on COVID-19 in Brazil. Papers on Social Representations 2020;29:4.1-4.18.

14. Pereira C, Medeiros A, Bertholini F. Fear of death and polarization: political consequences of the COVID-19 pandemic. Rev Adm Pública 2020;54:952-68.

15. Santos LS. Dilemas morais da gestão pública brasileira no enfrentamento da pandemia do novo coronavírus. Rev Adm Pública 2020;54:909-22.

16. Castro K, Moura E, Pereira E, et al. Palliative care: epidemiological profile with a biopsychosocial look on oncological patients. BrJP 2019;2:49-54.

17. Silva R, Oliveira E, Oliveira J, et al. Perspectiva de la familia/cuidador sobre el dolor crónico en pacientes con cuidados paliativos. Revenf 2019;38:e37086.

18. Couto AM, Caldas CP, Castro EAB. Cuidador familiar de idosos e o Cuidado Cultural na assistência de Enfermagem. Rev Bras Enferm 2018;71:959-66.

19. Humerez D, Ohl R, Silva M. Saúde mental dos profissionais de enfermagem do brasil no contexto da pandemia COVID-19: ação do conselho nacional de enfermagem. Cogitare Enferm 2020;25:e74115.

20. Corrêa K, Oliveira J, Taets G. Impacto na Qualidade de Vida de Pacientes com Câncer em meio à Pandemia de Covid-19: uma Reflexão a partir da Teoria das Necessidades Humanas Básicas de Abraham Maslow. Revista Brasileira de Cancerologia 2020;66:e-1068.

21. Bergbom I, Pettersson M, Mattsson E. Patient clothingpractical solution or means of imposing anonymity? J Hosp Med Manage 2017;3:1-6.

22. Dejours C, Abdoucheli E, Jayet C. Psicodinâmica do trabalho: contribuições da escola dejouriana à análise da relação prazer, sofrimento e trabalho. 1st ed. São Paulo: Atlas, 1994.

23. Dejours C. A loucurado trabalho, estudo de psicopatologia do trabalho. 5th ed. São Paulo: Cortez, 2009.

Cite this article as: de Azeredo Siqueira AS, Teixeira ER, de Oliveira da Cunha DA, Barcellos Santiago F, Ferraz Kirby EE, Lima Neves LM. COVID-19 in oncology palliative care: psychological stress from the perspective of psychodynamics at work. Ann Palliat Med 2021;10(5):5260-5269. doi: 10.21037/apm$21-56$ 